\title{
Polysemy: Current Perspectives and Approaches
}

Ingrid Lossius Falkum \& Agustin Vicente

\section{Preliminaries}

Polysemy is usually characterized as the phenomenon whereby a single word form is associated with two or several related senses, as in (1) below:

(1) draw a line; read a line; a line around eyes; a wash on a line; wait in a line; a line of bad decisions, etc.

In this, it is contrasted with monosemy, on the one hand, and with homonymy, on the other. While a monosemous form has only one meaning, a homonymous form is associated with two or several unrelated meanings (e.g., coach; 'bus', 'sports instructor'), and is standardly viewed as involving different lexemes (e.g., $\left.\mathrm{COACH}_{1}, \mathrm{COACH}_{2}\right)$.

Polysemy is pervasive in natural languages, and affects both content and function words. While deciding which sense is intended on a given occasion of use rarely seems to cause any difficulty for speakers of a language, polysemy has proved notoriously difficult to treat both theoretically and empirically. Some of the questions that have occupied linguists, philosophers and psychologists interested in the phenomenon concern the representation of polysemous senses in the mental lexicon, how we should deal with polysemous words in a compositional theory of meaning, how novel senses of a word arise in the course of communication, and how hearers, usually effortlessly, arrive at the contextually appropriate sense on a given occasion of use.

The definition and delimitation of the polysemy phenomenon itself also remains a source of theoretical discussion across disciplines: how do we tell polysemy apart from monosemy on the one hand, and from homonymy on the other? At first glance, the contrast with monosemy is clearer: while a monosemous term has only a single meaning, a polysemous term is associated with several senses. However, the literature shows that distinguishing polysemy from monosemy is far from a trivial matter. A famous case in point is the debate between Jackendoff 
(1992a) and Fodor (1998) concerning the English verb keep. Jackendoff argues that keep must be polysemous, given that it has different meaning in constructions such as keep the money, keep the car in the garage, and keep the crowd happy. Fodor, on his side, argues in favour of a monosemy account of keep in which it means KEEP in all cases, and the apparent difference in meanings is simply an artefact of the different contexts in which the verb appears.

Several linguistic tests have been devised to distinguish polysemy from monosemy. Particularly well known is Zwicky and Saddock's (1975) identity test by conjunction reduction, where the conjunction of two different senses or meanings of a word in a single construction gives rise to zeugma. For instance, the verb expire has (at least) the two senses 'cease to be valid' and 'die', and so the sentence ?Arthur and his driving license expired yesterday is zeugmatic. Another type of test exploits the impossibility of anaphorically referring to different senses (Cruse, 2004a). For instance, in the sentence ?John read a line from his new poem. It was straight. the pronoun cannot simultaneously refer to a sense of line combinable with the modifier straight (e.g., 'long, narrow mark or band') and the sense of line in the previous sentence ('row of written/printed words'], which suggests that we have to do with a case of lexical ambiguity. However, such tests for identity of meaning do not give clear-cut answers (for a review, see Geeraerts, 1993). In particular, only a slight manipulation of the context can yield a different result, as shown by the following example (Norrick, 1981: 115):

(2) a. ? Judy's dissertation is thought provoking though yellowed with age. b. Judy's dissertation is still thought provoking though yellowed with age. While the sentence in (2a) is zeugmatic - apparently due to the use of Judy's dissertation to refer to a type of informational content in the first conjunct and a physical object in the second conjunct - no zeugmatic effect occurs when the sentence is slightly altered as in (2b). Furthermore, the tests typically do not distinguish between polysemy and homonymy - that is, they do not distinguish between senses or meanings that are related and those that are unrelated - both 
of which come out as instances of a more general phenomenon of lexical ambiguity.

Many scholars see the distinction between polysemy and homonymy as being of little theoretical interest (e.g., Cruse, 1986; Kempson, 1977), and the significant distinction as being that between lexical ambiguity and monosemy. However, there is recent work in psycholinguistics that suggests that related and unrelated senses (or meanings) may be associated with different storage profiles (e.g., Klepousniotou \& Baum, 2007; Rodd, Gaskell, \& Marslen-Wilson, 2002), although the results are to some extent conflicting (e.g., Foraker \& Murphy, 2012; Klein \& Murphy, 2001). An important reason for the different results obtained is that polysemy itself is a multifarious phenomenon, and it is not always clear that the experimental items used across studies are comparable with respect to the form of polysemy they exhibit.

Finally, the linguistic tests have also been used to distinguish lexical ambiguity (including homonymy and 'accidental' polysemy) from so-called 'logical' polysemy (see below) (Asher, 2011), on the assumption that the different senses of a logically polysemous expression can be felicitously conjoined and anaphorically referred to by use of a pronoun. An example of successful conjunction is the sentence Lunch was delicious but took forever, where lunch refers consecutively to a type of food and to an event type. An example of a felicitous anaphora is found in the sentence That book is boring. Put it on the top shelf, where the pronoun it refers anaphorically to the physical object sense of the noun book, even though the sense of book activated in the previous sentence is the information sense. In contrast, lexically ambiguous terms give rise to zeugma when conjoined and do not allow for anaphoric reference. Used this way, the conjunction and the anaphoric reference tests seem capable of distinguishing some types of lexical ambiguity (homonymy and accidental polysemy) from others (logical polysemy), but not between logical polysemy and monosemy.

It is customary in the literature to distinguish between regular or logical polysemy, on the one hand, and irregular or accidental polysemy, on the other 
(Apresjan, 1974; Asher, 2011; Pustejovsky, 1995) ${ }^{1}$. In a classic paper, Apresjan (1974: 16) described the polysemy of a word $A$ in a given language with the meanings $a_{i}$ and $a_{j}$ as being regular if "there exists at least one other word B with the meanings $b_{i}$ and $b_{j}$, which are semantically distinguished from each other in exactly the same way as $a_{i}$ and $a_{j}(. .$.$) ." Examples in English are terms for animals,$ which (with some exceptions) can be used to denote either the animal or the meat of that animal (e.g., chicken, rabbit, turkey, etc.), terms for containers used to denote either the container itself or its contents (e.g., He drank the whole bottle/glass/mug, etc.), names of artists used to denote their works (e.g., Proust is on the top shelf, Mary owns a $\underline{\text { Picasso) }}$ ) and so on. In formal semantic and computational approaches, regular polysemy of this kind is typically analysed as being generated by lexical rules, in this way accounting for the productivity and cross-linguistic availability of the patterns of sense extension and the same time avoiding a listing of all senses for the words in question (Asher \& Lascarides, 2003; Copestake \& Briscoe, 1995; Gillon, 1992; Kilgarriff, 1992; Ostler \& Atkins, 1992; Pustejovsky, 1995). While this is certainly one way of accounting for the regularity involved in this sort of polysemy, there are also other, more pragmatically-oriented explanations, which we will discuss further below.

Irregular polysemy, on the other hand, is described by Apresjan (1974: 16) as cases where the semantic distinction between the meanings $a_{i}$ and $a_{j}$ for a word A cannot be found in any other word of the given language. The English verb run

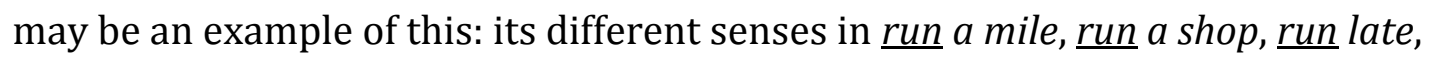
run on gasoline, etc. seem idiosyncratic to this particular lexical item, and may each have arisen as a result of different lexical semantic or pragmatic processes, such as for instance specification, loosening, metaphorical extension, and so on.

However, the distinction between regular and irregular polysemy is not clear-cut either. As to irregular polysemy, there appears to be degrees of irregularity, with some cases being clearly idiosyncratic, and others constrained by the way meaning chains tend to develop (Sweetser, 1990; Taylor, 2003). For instance,

\footnotetext{
${ }^{1}$ It is also possible to distinguish regular from logical polysemy, logical polysemy being a subclass of regular polysemy, which is operationally defined as polysemy which passes the conjunction and anaphoric reference tests (Asher, 2011).
} 
cognitive linguists have offered exhaustive accounts of the polysemy of prepositions (see, e.g., Brugman 1988 for a pioneering account of the polysemy of English over) where they bring to light a series of meaning chains, starting with a preliminary, usually embodied, sense, which extend to new domains in semi-predictable ways. Also, some regular polysemy can be characterized as idiosyncratic or accidental, at least in the sense that it may be idiosyncratic to particular languages or language communities and its existence seems to be a matter of historical accident. One example may be Nunberg's (1979) much-cited ham sandwich-case, where waiters in a restaurant exploit the pattern 'meal-forcustomer' in making reference to their customers (e.g., The ham sandwich wants his bill). This seems to be an instance of regular polysemy in Apresjan's (1974) sense, of non-logical polysemy in Asher's (2011) sense, and could also be described as a case of idiosyncratic polysemy (even though one usually talks about idiosyncratic and irregular polysemy interchangeably).

Recent work on polysemy is as varied as is the phenomenon itself, both in its focus and methods. In general linguistics, polysemy received little attention for many years, mainly due to the predominance of generative grammar with its focus on the sentence as the central unit of meaning. However, with the emergence of the cognitive grammar during the 1980s polysemy emerged on the research agenda as a key topic in lexical semantics, in particular as a result of the pioneering studies conducted by George Lakoff (1987) and Claudia Brugman (1988) on the polysemy of English prepositions. Alongside the cognitive linguistic movement, polysemy has become a central topic of investigation within many formal and computational semantic approaches, starting with Pustejovsky's (1995) seminal work on the topic and most recently culminating in Asher's (2011) monograph Lexical Meaning in Context. With their focus on semantic compositionality, these accounts have focused mainly on logical polysemy, which seems to be more tractable from a formal/computational point of view. In addition to these two main trends in the research on polysemy, much of the work conducted within the relatively new field of lexical pragmatics has a direct bearing on the topic (e.g., Carston, 2002; Recanati, 2004; Wilson \& Carston, 2007). These approaches are mainly concerned with how polysemy 
relates to the interaction between linguistically-encoded content and contextual information in the derivation of speaker-intended meanings. In the psycholinguistic literature, polysemy has attracted interest due to the issues it raises for semantic representation, in particular, how the mental lexicon represents polysemy compared with homonymy, a distinction that has been investigated using different methods and techniques (e.g., Klein \& Murphy, 2001; Klepousniotou \& Baum, 2007; Pylkkänen, Llinás, \& Murphy, 2006). Finally, recent lexicographical approaches have focused on creating tools for extracting senses from corpus data (Geeraerts, 2010).

Until recently there has been little interaction between these different approaches to the study of polysemy. However, we think a common ground between them is now emerging, where we are beginning to see the promise of some unified treatments, with psycholinguists working with proposals from computational semantics and lexical pragmatics, and theoreticians showing increased interest in experimental results and psychological models. This volume aims to make advancement in this interdisciplinary line of study by bringing together research done in each of the areas described above. In the next section, we will outline the main parameters of the current debate in the new 'common ground', by focusing on two key questions which - either explicitly or

implicitly - have occupied most researchers working on polysemy: semantic representation and mental storage on the one hand, and the mechanisms of polysemy generation on the other. In Section 3, we present a recent lexicographical approach to the study of polysemy.

\section{Approaches to polysemy representation, storage, and generation}

\subsection{The sense enumeration lexicon}

The 'sense enumeration lexicon hypothesis' holds that all the different senses of a polysemous expression are represented in the mental lexicon. That is, there is a distinct representation for each sense of a polysemous word. The model was first proposed by Katz (1972), it underlies most of the early work in the cognitive grammar tradition (Brugman, 1988; Brugman \& Lakoff, 1988; Lakoff, 1987) and has lately been advocated by some psycholinguists (Foraker \& Murphy, 2012; 
Klein \& Murphy, 2001). In this model, the distinction between polysemy and homonymy is attenuated. Although defenders of the model may distinguish between polysemy and homonymy based on whether the different senses or meanings and thought to belong to a single lexical entry or not, this difference does not seem to carry much weight at the level of storage or of processing. In both polysemy and homonymy, senses or meanings are thought to be stored as distinct representations. And when it comes to processing, polysemy resolution, just as homonymy resolution, consists in selecting a sense or a meaning from within a list of distinct senses or meanings associated with the word form.

The sense enumeration model is prima facie the simplest way to deal with polysemy on theoretical grounds. If the aim of semantics is to build a compositional model of linguistic interpretation, then it seems that the least problematic option is to postulate that all variability in the semantic contribution of one expression is due to that expression's having different senses stored as distinct representations. Speakers and hearers have to select one of these senses but once this is done, the compositional process can proceed as normal. However, even from a purely theoretical point of view, the sense enumeration hypothesis turns out to be problematic.

First, many words have a large number of different senses. Postulating that the full range of senses for each word is stored entails a (potentially) indefinite proliferation of mentally stored senses in order to cover the range of uses of words (as an illustration, see Brugman, 1988, who identifies nearly a hundred different uses of the English preposition over). Not only does this place an enormous demand on the storage capacity of the language user, but it also fails to distinguish between those aspects of meaning that are part of the word meaning proper and those that result from its interaction with the context, a problem sometimes referred to as the 'polysemy fallacy' (Sandra, 1998). Second, polysemy is pervasive, which means that sentences typically contain several polysemous terms. Selection of a sense for one expression would depend on the selection of senses for the rest. If speakers and hearers have to access all the possible sense combinations for each sentence, then processing just a simple sentence would be costly. 
The sense enumeration hypothesis faces some empirical problems as well. As we have already mentioned, it does not distinguish between polysemy and homonymy. However, experimental evidence from psycholinguistics suggest that while the different senses of polysemous expressions prime each other, i.e., the activation of one sense activates the others as well, homonymy resolution involves competition, rather than priming (Klepousniotou, Titone, \& Romero, 2008). Furthermore, polysemous expressions whose senses are closely related show a processing advantage in that words with multiple related senses tend to be responded to faster than words with fewer senses (Azuma \& van Orden, 1997; Klepousniotou \& Baum, 2007; Rodd et al., 2002). However, if all senses are represented distinctly in the mental lexicon, then having more senses should be either disadvantageous for the speed of response (if the hearer has to access all the different senses and pick out the relevant one), or have no effect at all (if only the relevant sense is accessed). Finally, work done by Steven Frisson with the eye-tracking technique suggests that while homonym resolution seems to require immediate selection one of the homonymous meanings, polysemy resolution appears to involve the initial activation of an underspecified meaning before the reader homes in on the appropriate sense on the basis of the context that follows (see Frisson, 2009, for a summary).

Recently, however, some psycholinguists have vindicated the sense enumeration model on empirical grounds (Foraker \& Murphy, 2012; Klein \& Murphy, 2001; but cf. Pylkännen, Llinás \& Murphy, 2006). Klein and Murphy (2001) investigated the representation of a set of polysemous words using behavioural tasks. They asked their participants to make a sense/nonsense judgement on phrases containing a polysemous word (e.g., daily paper, shredded paper), and found that participants were faster and made fewer errors in their sensicality judgements when the target phrase had been primed by a phrase using a consistent sense (e.g., [daily paper], liberal PAPER) than by one using an inconsistent sense (e.g., [daily paper], shredded PAPER), i.e. a consistency effect. The lack of priming effects found for the senses of their polysemous words led them to conclude that these were represented in the same way as homonyms. 
In a follow-up study, Foraker and Murphy (2012) present results from an eyetracking study which suggest that not all polysemous expressions are represented in the same way: while some polysemes indeed behave as homonyms, others may require a different approach (see also Klepousniotou et al., 2008). For instance, in the case of paper, the senses appear to be quite distant from each other, which may be why they behave much like the meanings of homonymous terms (i.e. show signs of competition rather than priming). However, more closely related senses such as the animal and meat senses of animal terms (chicken, rabbit, turkey, etc.) seem to prime each other. On Foraker and Murphy's view, a sense enumeration model might still be able to accommodate this pattern of results but, as they suggest, "it is possible that questions about how senses are activated do not have a single answer but differ depending on the word and the nature of the polysemy" (2012: 424). It could be added that the question of storage may also depend on the word and the nature of the polysemy.

Although the studies by Klein and Murphy (2001) and Foraker and Murphy (2012) provide some experimental evidence in favour of sense enumeration, some methodological problems with their experiments have been pointed out (Klepousniotou et al., 2008). In particular, these concern the experimental items used, whose polysemy status is not always clear and contain no distinction between nouns, adjectives and verbs. Frisson (this volume) aimed at replicating the experiments by Klein and Murphy (2001) and Foraker and Murphy (2012) using a more controlled set of stimuli, and to test whether sense dominance (i.e., frequency) could have played a role in the consistency effect found by these experiments. Given the evidence that sense dominance affects the processing of homonyms, with the more frequent meaning being easier to process than the subordinate meaning (e.g., Rayner \& Duffy, 1986), we should expect to find the same effect for polysemes if they are represented like homonyms. Frisson's two experiments consisted in a sensicality task (cf. Klein \& Murphy 2001) and an eyemovement study (cf. Foraker \& Murphy 2012). The stimuli were restricted to nouns that were polysemous between an abstract and a concrete sense (e.g., book, manuscript, notice, journal, etc.), and where, according to the British 
National Corpus, ${ }^{2}$ the abstract sense was always the most frequent (i.e., dominant).

First, in the sensicality task, subjects were presented with a prime noun phrase in which the adjective focused on either the concrete (e.g., bound book) or the abstract (e.g., scary book) sense. Then they were asked to make a sensicality judgement about a target noun phrase in which the adjective focused on either the consistent (e.g., [well-plotted book], scary BOOK), or the inconsistent (e.g., [bound book], scary BOOK] sense. The results showed a clear consistency effect, with increased processing time in the inconsistent condition compared with the consistent condition, but no effect of either sense dominance or direction of sense switch (concrete to abstract or abstract to concrete) in the inconsistent condition. While the absence of a processing advantage for the dominant sense is difficult to accommodate for a sense enumeration theory, the results are compatible with a relevance theory-inspired view (e.g., Sperber \& Wilson, 1986/1995; Wilson \& Sperber, 2004) which predicts that the disambiguating information provided by the adjective should make processing of either sense equally easy, but that revising an interpretation that has been established as optimally relevant should be costly.

Second, in the eye movement study, subjects were exposed to similar polysemous words in a regular reading task. There were three conditions: The neutral conditions aimed at testing how quickly a specific sense is assigned to a polysemous word without prior contextual indication (Neutral-dominant: Mary told me that the book was scary, Neutral-subordinate: Mary told me that the book was bound). The repeat conditions aimed at testing the effect of sense repetition on ease of processing (Repeat-dominant: Mary told me that the science-fiction book was scary, Repeat-subordinate: Mary told me that the gift-wrapped book was bound). Finally, the switch conditions tested whether switching from one sense involves an extra processing cost (Switch-dominant: Mary told me that the bound book was scary, Switch-subordinate: Mary told me that the scary book was bound). The most important results were as follows: In the neutral conditions, subjects did not have more difficulty disambiguating towards the subordinate

\footnotetext{
${ }^{2}$ http://www.natcorp.ox.ac.uk
} 
sense than toward the dominant sense of the polysemous noun. This goes against the sense enumeration hypothesis and a relevance theory-inspired view, which would predict that the most frequent sense should be faster to access. ${ }^{3}$ In the repeat conditions, subjects spent more time reading the polysemous noun than in the neutral condition, but the time to select a particular sense was not affected by sense frequency. This also goes against both sense enumeration and a relevance theory-inspired view, which would predict faster reading times when a sense has already been accessed than in the neutral condition. Finally, the results from the switch conditions showed that processing was more difficult in this context than in the neutral context, and also that switching from a subordinate to a dominant sense induced a greater cost than vice versa, a result compatible with both sense enumeration and a relevance theory-inspired view. As an explanation of this asymmetric difficulty, Frisson suggests that readers might 'commit' (Frazier \& Rayner, 1990) more strongly to the concrete (subordinate) sense, making it harder to switch to a different interpretation. The reader might assume that if the writer has made the effort to focus on a less common sense, he should pay more attention to it. Frisson takes the results from his eye-movement study to be best explained by a model that takes polysemous expressions to initially activate an underspecified, abstract representation which encompasses all its established senses (in the present case this would include both the content and the physical object senses), and where context is then used to 'home in' on the intended sense (see, e.g., Frisson, 2009). In the following section, we discuss this option in more detail.

\subsection{The one representation hypothesis}

The main alternative to the sense enumeration lexicon hypothesis is the socalled 'one representation hypothesis'. According to this hypothesis, the senses

\footnotetext{
${ }^{3}$ Frisson's use of the notion 'relevance theory-inspired view' reflects the fact that the predictions from actual relevance theory often cannot be stated in general terms like this, but may depend on a number of factors. One important factor in the present context is whether the book type of polysemy is hypothesised to involve a single concept or distinct concepts. If distinct concepts, we get the predictions that follow from Frisson's relevance theory-inspired view for the relation between dominant-subordinate senses in the neutral and repeat conditions. But if there is only a single concept associated with the book type of polysemy, which seems to be the dominant view in the literature (e.g., Cruse, 1986; Falkum, 2011; Nunberg, 1979; Pustejovsky, 1995), the predictions of relevance theory are likely to be very similar to those made by Frisson's underspecification hypothesis (see below).
} 
of a polysemous expression either belong to or depend on a single representation. The hypothesis that the different senses of a polysemous expression depend on a single representation is clearly more cautious than the claim that they belong to, i.e. are stored as part of, a single representation. In fact, most researchers who defend the one representation hypothesis espouse this more moderate claim. The general idea is that, when interpreting a polysemous expression, competent speakers access a semantic representation which acts as a gateway to the different senses. There are different ways to cash out this proposal, ranging from the decompositional account of Pustejovsky (1995), where senses are generated on the basis of informationally rich lexical representations, to Carston's (2012) recent proposal that the representation that speakers first access in encountering a word may simply embody some constraints on what the word may express (cf. 'pointers to a conceptual space', Carston, 2002).

In recent years, psycholinguists have debated two proposals that fall under the one representation approach, 'the core meaning hypothesis' and 'the underspecification hypothesis'. However, it is not clear how much these two hypotheses differ, since their more concrete commitments still remain to be spelled out. We think that the core-meaning approach can be understood as a kind of underspecification approach, and in what follows we will treat it that way.

Underspecification accounts have been proposed to deal with a variety of phenomena, including scope ambiguities (Egg, 2011) and alleged type-shifting constructions (de Almeida \& Dwivedi, 2008). The underspecification approach to polysemy holds that hearers, when encountering a polysemous expression, do not opt for a particular sense but rather access an underspecified representation which is enriched only if required by the context. This hypothesis has been defended by Steven Frisson in a number of papers (for a review, Frisson, 2009), although he is not very specific about what exactly the hypothesis amounts to. According to Frisson, it is compatible with views as different as Pustejovsky's (1995) generative lexicon (more specifically, his notion of qualia structures), Carston's minimalist proposal (2012), as well as the core meaning approach 
holding that the representation accessed is some abstract meaning that is shared by all the different senses of a polysemous word (Ruhl, 1989). In our view, the most important difference between these three options lies in what we can call 'thin' and 'rich' semantics, i.e. between minimalist and core meaning proposals on the one hand, and accounts inspired by Pustejovsky's rich lexical representations on the other hand.

\subsubsection{Thin semantics}

Let us start with 'thin semantics'. Thin semantics is the view that lexical, or standing meanings of words are impoverished with respect to their occasional meanings (i.e. the meanings they express on a certain occasion of utterance, which is their contribution to the truth-conditions of the sentential utterance). This view has a long tradition (see Maienborn, 2011), and has recently gained momentum by being associated with contextualist approaches and the so-called 'semantic underdeterminacy thesis' (Carston, 2002), according to which the semantic content of a sentential utterance underdetermines its truth-conditional meaning. Although the thesis is compatible with different views on lexical meaning, one natural approach is to postulate a thin semantics, according to which lexical meanings only contain information which constrains the range of concepts that words can be used to express (Carston, 2012; Travis, 2008), or provide semantic potentials, which may be summary representations of past uses of words which guide new uses (Recanati, 2004).

These versions of the underspecification view suggest a discontinuity between underspecified semantic representations and the concepts word-tokens express. Other proposals in the thin semantics camp do not posit this kind of separation. For instance, Bierwisch and Schreuder (1992) distinguish between semantic and conceptual representations, where semantic representations are taken to consist of sets of necessary conditions, which are typically compositionally enriched through feature addition in order to yield a truth-conditional content. Two papers in this collection -- those by Alexandra Spalek and Vyvyan Evans -explicitly defend a thin semantics version of the underspecification approach to polysemy. We will return to Evans's approach in Section 2.4. 
In her analysis of two Spanish verbs, cortar ('cut') and romper ('break'), Spalek (this volume) argues for an underspecified, thin lexical meaning which is enriched in composition, and shows how the (occasional) meaning of these verbs depends on the kind of internal argument they take. Both verbs can combine with nouns denoting physical objects, but they also accept abstract themes, such as states, processes, or norms. The meaning they express is clearly different depending on the kind of object they combine with, but the differences also extend to the patterns of alternations they admit and the selectional restrictions they impose on the external argument. For instance, while cortar admits the anticausative alternation in cortar la comunicación ('cut the communication'), romper la ley ('break the law') only admits agents as subjects (see also Rappaport Hovav, 2014).

Spalek further argues that neither a sense enumeration model nor a contextualist approach à la Recanati (2004), which appeals to pragmatics (and in particular to the process of 'free enrichment') to explain the diversity of occasional meanings, can explain her data. According to Spalek, the variability in the meanings expressed by these verbs, as well as the differences in their grammatical behaviour, should be given a compositional, semantic explanation in terms of Pustejovsky's (1995) notion of 'co-composition', where the meaning of the verb is specified in combination with the meaning of the internal argument that it takes. Spalek gives a formal account of the process of co-composition based on Modern Type Theory (MTT: see below), using very fine-grained types. According to her, verbs such as cortar and romper should be seen as being represented as dependent types, whose specific interpretations are determined by the type of the entity that functions as the theme or object of the verb.

Spalek concludes her paper by offering some hints about what the underspecified, lexical meanings of cortar and romper might be. She holds that both verbs express a change-of-state in which an entity which exemplifies some kind of connectedness (temporal or spatial) undergoes disconnection. The difference between cortar ('cut') and romper ('break') has to do with whether this disconnection is controlled, as in the 'cut' case, or not. The lexical meanings she proposes are clearly thin and underspecified in comparison with the 
occasional meanings, and at the same time capture the elements of meaning that are common to all the uses of these verbs. In this way, Spalek's proposal could also be seen as exemplifying a core-meaning approach.

The 'core meaning hypothesis', as we understand it, is the hypothesis that the semantic representation of polysemous terms consists in a set of features or a common core that is shared by all senses of a polysemous term. As mentioned, this is what qualifies Bierwisch and Schreuder's (1992) two-level semantics and Spalek's proposal (this volume) as core-meaning approaches. Another prominent example is Jackendoff's (1992a) analysis of the polysemy of keep, according to which the meaning of this verb is CAUSE [STATE OF $X$ THAT ENDURES OVER TIME], with $\mathrm{X}$ taking values from different semantic fields: possession, location, mental state, etc.

Some psycholinguists also defend a core meaning approach. For instance, Klepousniotou et al. (2008: 1535) describe a core meaning as "a memory structure encompassing all semantic features that are common across multiple senses of a polysemous word (e.g., for the word 'rabbit', a core representation might include [+ANIMATE, +FARM ANIMAL, +EDIBLE, +MEAT]." The idea is that if the senses of a polysemous word typically overlap, this could explain why they prime each other and why words with many senses appear to be easier to process than words with few senses.

Plausible as it may seem, the core meaning approach has several shortcomings. First of all, it has a limited reach. As Klepousniotou et al. (2008) acknowledge, it can explain the cases where the senses of a polysemous term are closely related, but not the cases where the senses are 'distant' and behave more in line with homonyms (e.g., paper; cf. Klein and Murphy, 2001). However, its reach may even more limited than this. As Foraker and Murphy (2012) argue, it is not the case that rabbit retains the four features described above in the sentences I saw a rabbit running and I am cooking rabbit. In the case of a running rabbit, the rabbit is not edible, and it is not meat. In the case of rabbit meat, the rabbit is not animate. The same seems to hold for many other instances of closely related senses, such as for instance the polysemous patterns container-for-content $(\underline{T h e}$ 
$\underline{D V D}$ is one-hour long, The DVD is scratched), artist-for-works (My father was a friend of Picasso, I like that $\underline{\text { Picasso, }}$, etc., or the numerous different senses of school ('building', 'institution', etc.; cf. Frisson, 2009).

However, these data should not make us discard the core-meaning approach entirely. On the one hand, the core meaning approach does not need to commit to there being a common core which is present in all uses of a polysemous expression. The core could consist in a cluster of features, most of which are present in most uses of the word. On the other hand, it may be that some cases of polysemy are more difficult to approach in terms of common cores than others, and that different types of polysemy may require different treatments. For instance, it may be more difficult to find common cores in cases of regular nominal polysemy than in cases of verbal polysemy.

\subsubsection{Rich semantics}

The other alternative is the 'rich semantics' version of the underspecification approach. According to this view, lexical meanings are rich in conceptual information, and, typically, hearers have to select only a part of or an aspect of the whole informational content provided by lexical meanings. An example of this approach is Pustejovsky's (1995) generative lexicon theory, which has been widely influential. According to Pustejovsky (1995), lexical meaning involves a structure consisting of four levels of representation: 'argument structure', 'event structure', 'qualia structure', and 'lexical inheritance structure'. The qualia structure of a lexical item (usually exemplified by nouns) is the hallmark of Pustejosky's theory and includes information about how the object came into being (agentive role), what kind of object it is (formal role), what it is for (telic role), and what it is constituted of (constitutive role). Pustejovsky (1995; see also Asher, 2011) restricts the notion of polysemy to logical polysemy, and postulates a special type, 'dot objects', in his type theory to account for it. Dot objects are lexical representations composed of two or several different senses: for instance, the noun book is a dot object with a 'physical object' sense and an 'information' sense, physical object•information, which gives rise to the polysemous senses in (3) below: 
(3) a. The book is sitting on the coffee table. ('physical object')

b. John found the book interesting. ('information')

c. That book with the gorgeous cover is really good ('physical object' + 'information')

In this theory, the different senses of a polysemous noun are represented as parts of a structured representation, so there is a core meaning which explains the polysemy of the noun. However, this rich core meaning is not equally active in all its uses.

In some accounts inspired by the Pustejovskyan proposal, qualia structures are thought to provide 'aspects' or 'facets' (that is, different ways of seeing a given entity), which are also the senses that enter into truth-conditional compositions (Cruse, 2004b; Frisson, 2009; Paradis, 2004), an idea reminiscent of Langacker's (1984) notion of 'active zones' (see also Falkum, 2011: 181-193). For instance, the polysemy of door in Mary walked through the door ('aperture'), and Mary painted the door ('physical object') can be explained by reference to different highlighted aspects or facets of the qualia structure of door: its constitutive quale ('aperture'), in the first case, and its formal quale ('physical object'), in the second. A similar account can be given for the various senses of school (Frisson, 2009). The noun school can stand for a building (The school needs a refurbishment), the place you take your children to (John made many friends at

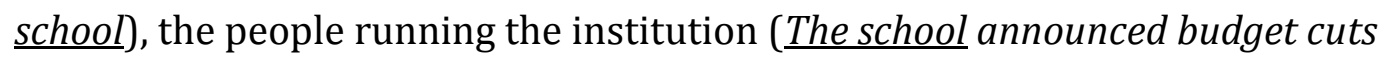
next year), and so on. One possibility is that all these senses are stored together and form part of a structure - a SCHOOL concept - which accounts for the relationship between all these senses. When the context brings to the fore one of them, the other senses will also be primed but remain less active than the one highlighted (see also Vicente \& Martínez-Manrique, 2015).

Vicente (this volume) develops this view and applies it to some of the so-called 'Travis cases' (Travis, 2008), which are typically used to support the semantic underdeterminacy thesis mentioned above, and more specifically the thin semantics version of it. In the most discussed Travis case we are asked to consider two different occasions where the expression type The leaves are green 
is uttered by a woman called 'Pia'. In the first occasion, Pia is talking to a photographer who needs some green leaves for her picture. Pia has decided to paint green some russet maple leaves. Still, in that context, her utterance of The leaves are green is judged to be true. However, then comes along a botanist looking for green leaves. Referring to the very same leaves, Pia says again: "The leaves are green". This time her utterance is judged to be false. Vicente suggests that it is possible to treat at least some of these cases as instances of polysemy, in particular, as nominal polysemy, where the aspects highlighted are related to two different ways of looking at objects which belong to kinds: (i) as what they essentially are, and (ii) as the way they appear. We believe that objects which belong to sortal kinds have essences, and that some of the properties that objects have are causally connected to their essences. However, we also know that it is possible to change the properties that an object has, even those properties linked to its essence (e.g. we can change the colour of the leaves from red to green). Thus, when we are told that a certain object has a certain property, it is always possible to ask: does it have that property in the sense of intrinsically having it, or does it have it only in the sense that it only displays it?

Vicente proposes that the variation exemplified by the best known Travis cases can be subsumed under the following generalisation: If we have an object $O$ of kind $K$, and a property $P$ which is causally linked to the essence that $O$ has in virtue of being a $K$, then 'Det $K$ is $P^{\prime}$-- where 'Det $K$ ' refers to $O$-- is ambiguous between two readings, which roughly are: $O$ is intrinsically $P$, and $O$ looks, or is right now, $P$. Thus, a sentence such as That dog is dangerous could mean that the dog is dangerous as such (e.g. because it is an aggressive pitbull terrier) or that it is dangerous right now (e.g., because it is nervous). As noted, the ultimate explanation appeals to the different aspects that the nominal offers for predication: the 'essential make-up' aspect, or the 'current look' aspect. These two aspects are grounded in world knowledge, but affect truth-conditional content (see also Vicente, 2012).

It is tempting, however, to think that there is no need to confront rich and thin semantics. It may be that some words have rich lexical meanings while others give access to scarcer information - as we have already suggested, it may be that 
nouns give access to a rich informational structure, whereas verbs typically have more open-ended meanings - and that semantic composition consists in combining rich and thin meanings. The generative lexicon theory (Pustejovsky, 1995) explains many cases of alleged polysemy in terms of such compositional mechanisms, where phrasal meanings arise as a result of interaction between the rich meaning of the nominal, and the thin meaning of the verb. An example is

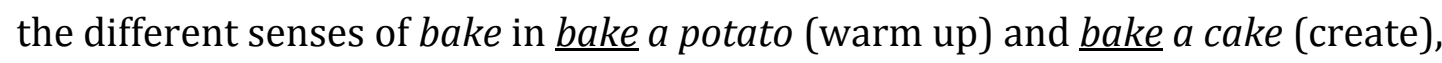
which is analysed in terms of the process of co-composition, involving an interaction between the schematic meaning of bake and the lexical information provided by the nouns (cakes are artefacts; potatoes are natural kinds). Spalek's contribution to the present volume (see above) may also serve as an illustration of this idea. The upshot would be that some types of polysemy (e.g. verbal) might be explained by appealing to thin semantics, while other types (e.g., nominal) might require an explanation in terms of a rich semantics.

\subsection{Literalist approaches}

Another type of approach to polysemy holds that polysemy resolution consists, in a first step, in accessing a concrete and semantically determined representation, which captures only one of the possible meanings of the expression, its 'literal meaning'. Once this literal meaning is accessed, speakers are driven towards other senses which are more consistent with contextual demands. We will refer to accounts of this type as 'literalist approaches'. It is possible to distinguish at least three basic approaches that could be said to fall under this description: rule-based approaches, the coercion hypothesis, and lexical pragmatic approaches.

\subsubsection{Rule-based approaches}

It is possible that when we process a polysemous expression we first access a literal sense and we then apply a conventional rule which takes us to another sense of that expression. An early manifestation of such a rule-based approach is Jackendoff's (1992b) analysis of the so-called 'statue' case: Imagine that we are watching a wax reproduction of the Beatles at Mme. Tussauds, and someone

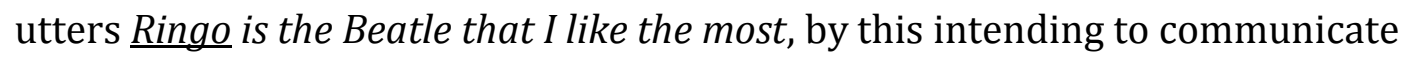
that 'Ringo is the wax figure that I like the most'. On Jackendoff's analysis, this 
use is possible because there is a linguistic rule that tells us that 'any NP can stand for an object or for a physical representation of that object'. On this view, then, there is a literal sense, let's say 'Ringo-the-drummer', and the other sense, 'the-statue-of-Ringo', is obtained through application of a linguistic rule.

In many formal and computational semantic approaches it has been common to analyse regular polysemy (cf. Apresjan, 1974) as being generated by an inventory of lexical rules (Asher \& Lascarides, 2003; Copestake \& Briscoe, 1992, 1995; Gillon, 1992, 1999; Kilgarriff, 1992; Ostler \& Atkins, 1992). For instance, Copestake and Briscoe (1995) suggest that the universal grinder (Pelletier, 1975), as well as a several conventionalised sub-cases of it (meat-grinding, furgrinding, and so on) might apply in typical instances of regular polysemy such as the following:

(4) a. There was rabbit all over the highway. (universal grinding)

b. Steven had rabbit for dinner. (meat-grinding)

c. The model wore rabbit on the catwalk. (fur-grinding)

In the examples in (4), the effect of the rules would be to create from a count noun denoting a physical object a mass noun with properties appropriate for an unindividuated substance (e.g., meat, fur, or general 'stuff'). The rules are seen as coming with specific interpretive predictions based on lexically stored information, so that, for instance, a mass use of an animal term would have a 'meat' sense as default. A parallel is often drawn between such lexical rules and derivational morphological processes: both appear to be 'blocked' by the existence of underived synonymous lexical forms (cf. glory/*gloriosity vs. veal/*calf) (Aronoff, 1976; Briscoe, Copestake, \& Lascarides, 1995). Proponents of this sort of approach often claim that lexical rules are necessary to explain the productivity of regular polysemy, and to account for the availability of 'default' senses in uninformative contexts and the parallel that might be drawn with morphological processes (Copestake \& Briscoe, 1992).

However, one might argue against such rule-based explanations that they have a rather limited reach, and are only able to account for a small subset of the range of phenomena falling under the polysemy label. Moreover, they allow for little 
flexibility of interpretation, and must appeal to pragmatics whenever a nondefault interpretation is intended by the speaker. A formal semantic account that has a wider scope than these rule-based explanations, in that it aims to explain a wider range of polysemy phenomena is the so-called 'coercion hypothesis' (Asher 2011, this volume), which we will discuss in the next section.

\subsubsection{The coercion hypothesis}

While a rule-based treatment has been proposed for a variety of cases of regular polysemy, one might question whether they form a kind in some interesting sense. For instance, while both the animal-for-meat (running rabbit vs. delicious

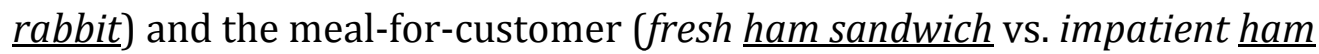

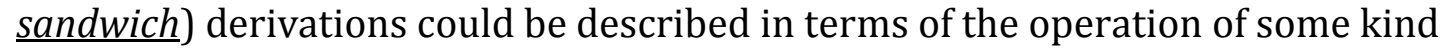
of conventional rule, the two cases differ in a number of ways. First, the meatgrinding rule seems more 'natural' in its application and cross-linguistic availability (see Srinivasan and Rabagliati, this volume) while the meal-forcustomer case has a strong conventional flavour, and may be idiosyncratic to certain language communities. Second, the two types of case behave differently on linguistic tests: while it is possible to say The rabbit was cute and delicious, one cannot say? The ham sandwich is impatient and delicious. Based on this, Asher (2011) suggests that some regular polysemy is best treated in terms of a process of coercion, while other types of regular polysemy (i.e., logical polysemy) require the postulation of dot objects (see also Pustejovsky, 2005). As we have seen, dot objects are complex representations, and exemplify an underspecification approach to polysemy. Coercion, however, is a mechanism which takes as its input a literal meaning, and forced by a type-mismatch when composing it with the other lexical meanings in the sentence, delivers a different meaning as output. That is, the coercion approach to polysemy could be seen as an instance of a literalist approach.

According to Asher (2011), we must postulate coercions whenever the dotobject approach fails. In his theory, linguistic tests for identity of meaning, such as co-predication and anaphoric binding, play an important role in distinguishing between dot objects and cases of coercion. Dot objects, by their complex nature, should allow both co-predication and anaphoric binding. If the noun book is 
represented as the complex type physical object•information, it should be possible to say The book is heavy but interesting or That book is awfully written. Put it back on the shelf. However, as we have just seen, there are cases of apparently regular polysemy that do not pass these tests, which suggests that the senses are not components of a dot object. According to Asher, these can be explained as coercions.

In his contribution to the present volume, Asher focuses only on coercion and apparently retreats from his previous commitment to dot objects. The data he presents reveal that it is difficult to give a unified explanation of coercion and to draw a clear distinction between logical polysemy and coercions. While some cases of coercion allow anaphoric binding to the coerced material, others typically do not, but the results are not clear-cut. Asher presents the example of bottle (which, in previous accounts was analysed as a dot object) as a case of coercion where anaphoric reference to the coerced material is possible. For instance, the sentence John brought a bottle. It was yummy is clearly felicitous, even though bottle (coerced by the selectional restrictions of the predicate yummy) has a shifted meaning, referring to the content of the bottle. A case where the coerced material is typically unavailable for later reference is the 'verb + noun to verb + event' coercion, as for instance, ?Jill started a book, which will last for years'. However, some contexts allow reference to the event, as in John is scared of starting War and Peace, because it will take him weeks. The same complexity can be observed for the 'meal-for-customer' pattern, where anaphoric reference clearly prefers the original denotation: ?The omelette left without paying, although it was very yummy is clearly odd. This is not always the case, though; for instance, it seems possible to say The omelette is enjoying it or The omelette with ham and cheese paid.

A theory of coercion has to explain this diversity, and in particular why the original denotation, which allegedly has undergone coercion, can still be reached via anaphora in many cases. To this end, Asher presents two formal systems which give different results: TCL (Type Composition Logic: see Asher, 2011) and MTT (Modern Type Theory: see Luo, 1994). TCL postulates two levels of meaning: type requirements or selectional restrictions, and denotations. It treats 
coercion not as a shift in the predicate or in the argument, but as type shift on the predication relation, i.e., on the way the predicate interacts with the argument, by inserting a functor around the argument. MTT, which differs from TCL mainly by treating common nouns as types (and not as predicates of type E-PROP), seems to be offering a version of argument shifting, though shifting in MTT operates very locally, and not upon the whole DP (it just shifts variables introduced by DPs). The result is that MTT allows both original and shifted meanings to be reached by anaphora. However, this result is not satisfactory, since both denotations are usually not available for anaphoric reference (see the examples above).

In the end, Asher proposes that we may have two coercion mechanisms. The first is local coercion, the second a spell out mechanism, which takes local coercions and fleshes them out into the TCL functors. Spell out mechanisms sometimes work without restrictions, but usually they require certain discursive environments, for instance, being embedded in an explanation, for the coerced material to be available (cf. the sentence John is scared of starting War and Peace, because it will take him weeks). The final part of the paper focuses on some issues raised by data involving the modification of nouns by adjectives, which apparently undergo meaning shifts without there being type mismatches (e.g. flat tire, flat surface, flat country, etc.).

Finally, it should be noted that coercion is usually thought to take time. Speakers have to retrieve a literal meaning, detect a type-mismatch, and solve it. There is some debate in the psycholinguistic literature as to whether this in fact happens in type shifting constructions such as I enjoyed the book (which may stand for I enjoyed [READING, or alternatively, WRITING, MENDING, BINDING, DUSTING, etc.] the book) (de Almeida, 2004; de Almeida \& Dwivedi, 2008; McElree et al., 2001; Pickering, McElree, \& Traxler, 2005). It seems that the account Asher presents here may have empirical consequences which psycholinguistics could confirm or falsify. 


\subsubsection{Lexical pragmatic approaches}

A radically different approach to polysemy can be found within the field of lexical pragmatics, which specifically studies the interaction between an expression's linguistically-encoded meaning and aspects of the context, and where context is not restricted, as it is in for instance Asher's proposal, to material provided by linguistic structure (e.g., Blutner, 1998; Bosch, 2007; Carston, 2002; Recanati, 2004; Wilson \& Carston, 2007). However, it shares with rule-based and coercion approaches the 'literalist' assumption that polysemous expressions typically activate a fully conceptual representation (a 'lexical concept'), which is used as a starting point for further inference. ${ }^{4}$

A central insight of lexical pragmatics is that word meanings typically undergo pragmatic modulation in the course of utterance interpretation. Consider the examples in (5)-(7):

(5) [University student]: I didn't get enough units. ('credit modules')

(6) It's boiling outside. ('extremely hot')

(7) Will is a fox. ('cunning, sly, devious..., etc.')

The idea is that while each of the interpretations in (5)-(7) is easily inferable from the context, none of them can be generated on the basis of linguistic context alone. The specification in meaning of the noun units in (5), the loose use of the verb boiling in (6), and the metaphorical broadening of the concept encoded by fox in (7), each requires the hearer to take the situational context into account in deriving the speaker-intended meaning. Lexical pragmatic processes such as these are thought to play a central role in giving rise to polysemy. The prevalence of polysemy in natural languages suggests that speakers and hearers might find it easier to extend already existing words to new functions than to invent new words for each sense, and lexical pragmatic processes are thought to play a key role in enabling communicators to do this. Indeed, some 'radical' pragmatic accounts tend to see polysemy as an epiphenomenon of pragmatic processes operating at the level of individual words: "In general ... polysemy is the outcome

\footnotetext{
${ }^{4}$ However, not all pragmatic approaches share this literalist assumption. As mentioned in Section 2.1.1 above, Carston $(2002,2012)$, who is one of the main defenders of a pragmatic (relevancetheoretic) account of polysemy, also espouses an underspecification approach (with a thin semantics) to lexical representations.
} 
of a pragmatic process whereby intended senses are inferred on the basis of encoded concepts and contextual information" (Sperber \& Wilson, 1998: 197).

Falkum (this volume) defends a pragmatic account of polysemy and argues against rule-based and linguistic approaches, on which polysemy results primarily from the operation of lexicon-internal processes. On her approach, the linguistic system plays a much more restricted role in providing only a minimal output, or clue, in the form of a lexical concept which the pragmatic inferential system uses as evidence to yield hypotheses about occasion-specific, speakerintended meanings. To take an example, consider the cases of adjectival specification in (8)-(10)(11):

(8) American Pastoral is a good book.

(9) To become a member of Billy's exclusive gang you had to have a good knife.

Mary bakes good cupcakes.

On linguistic, Pustejovsky-inspired accounts, the derivation of the different senses of the adjective good in the examples above would depend on a lexiconinternal, generative process of 'selective binding', enabling an adjective to make available a selective interpretation of an event expression contained in the lexical representation (or 'qualia structure') of the head noun, yielding the senses, 'good for reading', 'good for cutting', 'good for eating' respectively. According to Falkum, this sort of approach is too rigid, by allowing only lexicallyspecified information to contribute to the generation of context-dependent senses of the adjective. Consequently, it must appeal to pragmatics whenever a non-default interpretation is intended by the speaker, as in the following cases:
a. Chomsky's Aspects is a good book ('interesting').
b. That's a good book to use as a doorstop ('heavy enough').
c. I need a good book to put me asleep ('boring enough').
d. ...

In each of these cases good has a different sense, even though it is used to modify the same noun, book. And there are numerous other ways in which a book can be good ('easy to read', beautifully designed', 'useful to kill flies with', and so on). 
Falkum's point is that a pragmatic theory that is able to explain how such nondefault senses are derived should also be able to handle that part of the interpretive work that linguistic accounts do adequately. At the same time, she claims, it avoids many of the problems that have been discussed in connection with rule-based accounts, in particular with respect to interpretive inflexibility and overgeneration (Bosch, 2007; de Almeida \& Dwivedi, 2008; Falkum, 2007; Fodor \& Lepore, 2002). She suggests that the relevance-theoretic framework (Carston, 2002; Sperber \& Wilson, 1986/1995; Wilson \& Sperber, 2004, 2012) may be well suited for this task, and proposes an alternative approach to polysemy, in which it is treated as a mainly communicative phenomenon, which arises as a result of lexical concepts underdetermining the situation-specific concepts that are communicated by them, as part of hearers' search for optimal relevance in the process of utterance interpretation. In each of the examples in (8)-(10) above, this would involve a narrowing of the concept linguistically encoded by the adjective good by a process of ad hoc construction (Carston, 2002; Wilson \& Carston, 2007), which takes as input encyclopaedic information activated by the lexical concepts in the utterance, as well as any other relevant situation-specific assumptions activated by the utterance situation, in deriving the communicated, ad hoc concept, a process which is constrained by the hearer's occasion-specific expectations of relevance. On Falkum's view, the existence of polysemy has a strong motivation on this pragmatic-inferential account, where it arises by necessity to meet the communicative needs of speakers and hearers. Furthermore, she claims, the assumption that our pragmatic inferential ability plays a fundamental role in the development and proliferation of polysemy in verbal communication, provides a promising basis for a unified account of its role in several domains, including acquisition, diachrony and non-verbal forms of communication.

\subsection{Sense networks and LCCMs}

Most of the accounts presented so far, and particularly the rule-based and coercion accounts, analyse polysemy as a mainly linguistic phenomenon. Lexical pragmatic accounts, on the other hand, downplay the contribution of the linguistic system and emphasise instead the communicative aspect of polysemy, 
treating it as being governed by pragmatic inferential processes applying at the level of individual words. A third type of account, which we mentioned briefly at the beginning of this introduction and which has been very influential, takes polysemy to be not so much a linguistic or communicative phenomenon as an essentially cognitive one, which results from how our cognitive categories are structured more generally. The work that has inspired a host of accounts within the strand of linguistic known as 'cognitive grammar' is Lakoff and Brugman's pioneering studies of English prepositions (Brugman, 1988; Brugman \& Lakoff, 1988; Lakoff, 1987; see also Langacker, 1988). On this approach, linguistic categories are taken to be no different than other kinds of conceptual categories, and most word meanings are seen as a type of radial category (that is, a central, prototypical subcategory, combined with a set of non-central extensions) in which the different senses of a word are organised with respect to a prototypical sense. The paradigmatic example is the English preposition over (Brugman 1988):
a. The bird flew over the house. ('above and across')
b. The painting is over the couch. ('above')
c. The truck ran over the rabbit. ('across')
d. Sarah lives over the hill. ('on the other side')
e. Mary nailed a board over the hole in the ceiling. ('covering')
f. I will read the papers over the weekend. ('temporal')
g. John has a strange power over Mary. ('control')
h. ...

The idea is that over constitutes a radial category composed of a range of distinct but related senses, organised around a prototypical sense (assumed to be the sense in (12a) in Lakoff and Brugman's accounts) in a network structure. The different senses of over exhibit typicality effects so that more typical senses are located closer to the prototypical sense in the network, while less typical senses - derived from more typical senses through a set of cognitive principles for meaning extension, such as for instance metaphorical extension -- are located in its periphery. This gives rise to chains of senses, in which sense $a$ is related to sense $b$ in virtue of some shared attribute(s), sense $b$ is related to sense $c$, which 
is related to sense $d$ and so on. Sense relations, then, concern mainly adjacent members of the category, while members that are only indirectly connected in the semantic network may be very different in semantic content.

A key assumption of the version of the cognitive semantics approach we have described here is that sense networks are stored in the long-term semantic memory of language users. In this respect, this account of polysemy is a radical version of the approach we referred to above as the 'sense enumeration hypothesis', in that the full range of senses are taken to be stored in semantic memory (which is why it has sometimes been called 'the full-specification approach', cf. Evans \& Green, 2006). As we discussed, there are many problems with sense enumeration, and more recently, scholars working within the cognitive grammar framework have proposed a more moderate approach, taking into account the role played by the context in giving rise to novel senses of a word (Allwood, 2003; Taylor, 2006; Tyler \& Evans, 2003). In particular, Tyler and Evans (2003) suggest an account of polysemy they call 'the Principled Polysemy approach', which retains the idea that polysemous senses are represented in terms of sense networks centred around a prototypical sense, but includes a methodology for distinguishing between those senses that are stored in semantic memory and those that are pragmatically constructed in context.

In his contribution to the present volume, Vyvyan Evans develops a new approach to polysemy within the context of his Theory of Lexical Concepts and Cognitive Models (LCCM theory) (Evans, 2009, 2013). Evans's approach stands out among the cognitive linguistic approaches by virtue of its distinction between units of linguistic knowledge in the form of 'lexical concepts', which encode highly schematic contents and typically underspecify situation-specific meanings (in this sense, Evans' approach falls under the thin semantics version of the underspecification approach we dicussed above), ${ }^{5}$ and the non-linguistic, encyclopaedic knowledge in the form of so-called 'cognitive model profiles', that they give access to. A cognitive model is a is a coherent body of multimodal knowledge linked to a particular domain, and the cognitive model profile of a

5 Thus, Evans's notion of a lexical concept is different from the one we usually find in the literature, which refers to concepts expressed by lexemes. In Section 2.3.3 on pragmatic approaches, 'lexical concept' is used in this more common sense. 
lexical concept includes all the cognitive models to which it potentially gives access to, and constitutes what Evans terms the 'semantic potential' of a lexical concept (see Evans, 2009: 207, for more detail).

In his paper, Evans distinguishes between three types of polysemy, which he analyses within the framework of his LCCM theory: conceptual polysemy, lexical polysemy, and inter-lexical polysemy. These are illustrated below:

That book is heavy/illegible/boring/long. ('tome'/'text'/'level of interest'/'duration').

$$
\text { We are in a room/in pain. ('container'/'state') }
$$

a. We are in pain/in a room ('state'/'spatial')

b. We are on the run/on the sand. ('state'/'spatial').

According to Evans, in (13) we have an instance of conceptual polysemy, in which an open-class lexical item (book) takes on slightly different interpretations in different contexts (cf. the examples in (3) and (11) above). From the point of view of Evans's LCCM theory, this polysemy results from differential activation of regions of the cognitive model profile associated with the lexical concept [BOOK]. The idea is that [BOOK] gives access to at least the two primary cognitive models PHYSICAL STRUCTURE, relating to the physical artefact, and READING ACTIVITY, relating to the process involved in interacting with books, each of which consist of a large body of knowledge, or 'attributes' in Evans's terms. The cognitive model PHYSICAL STRUCTURE is thought to include a TOME attribute and a TEXT attribute, while the cognitive model READING ACTIVITY is thought to include a DURATION attribute, and a LEVEL OF INTEREST attribute. Evans accounts for the polysemy of book in (13) in terms of differential activation of these attributes in each context.

The lexical polysemy in (14) involves, according to Evans, distinct lexical concepts conventionally associated with the preposition in, more specifically a [PHYSICAL CONTAINER] lexical concept and a [PSYCHO-SOMATIC STATE] lexical concept. From the point of view of LCCM theory, a distinct lexical concept is characterised by having a unique lexical profile, that is, a specific set of semantic and grammatical selectional tendencies associated with it (e.g., the 
ungrammatical sentence *We're in war is taken as evidence that in cannot be applied to just any kind of abstract state). Evans then goes on to propose a principled methodology for examining the lexical profile of a putative lexical concept, and thereby for determining whether a sense involves a distinct lexical concept or not (for more detail, see Evans, this volume).

Finally, the novel concept of inter-lexical polysemy, exemplified by (15), involves systematic similarities between distinct lexical concepts associated with distinct lexical forms. For instance, as Evans observes, the 'state' lexical concepts associated with in and on appear to have quite different semantic selectional tendencies. While the 'state' lexical concept associated with in selects for semantic arguments involving emotional or psychological force (in love, in pain, etc.) - instantiating the [PSYCHO-SOMATIC STATE] lexical concept - these appear to be incompatible with on ( ${ }^{*}$ on love, ${ }^{*}$ on pain, etc.). However, states that are active for a delimited period of time, and those that appear to be under voluntary control and/or decision making, which Evans take to be instances of an [ACTIVE FUNCTIONING STATE] lexical concept (e.g., on duty, on sale, on the run etc.) are compatible with on but not with in (*in duty, *in sale, *in the run, etc.).

In the last part of his paper, Evans discusses the notion of a 'meaning spectrum', a novel construct within his theory, which he describes as a bundle of semantic parameters or atoms of meaning, which are conventionally associated with lexical concepts. Such meaning spectrums are a central component of the account that follows of how novel lexical concepts are construed in context and how derived senses become established in a language.

\subsection{Concepts and conventions}

Recently, Hugh Rabagliati and colleagues (e.g., Rabagliati, Marcus, \& Pylkkänen, 2011) have tried to test whether polysemy extension in regular polysemy is a matter of learning conventions, whether it is mainly motivated by our conceptual structure, as many cognitive linguistic accounts claim, or whether the best explanation involves a mixture of the two. Their previous work has presented 
and discussed psycholinguistic and developmental data. In this volume, Mahesh Srinivasan and Rabagliati introduce cross-linguistic evidence into the debate.

By far most research on polysemy, both of the regular and irregular kinds (cf. Apresjan, 1974) has focused on English. An important question for an account of the phenomenon is whether we find the same patterns of polysemy across different languages or whether languages differ with regard to their possibilities for polysemy.

Srinivasan and Rabagliati investigated a large number of systematic polysemy patterns found in English (e.g. 'animal for meat', 'material for artifact', 'container for content', etc.) and asked whether and how these were manifested crosslinguistically. More specifically, they were interested in whether such systematic patterns of polysemy show low, moderate or high cross-linguistic variability, whether attested senses of these patterns (e.g., chicken for chicken meat) are also found in other languages, and whether patterns that are generative in English are also generative in other languages (e.g., seagull for seagull meat). To investigate this, they conducted a cross-linguistic survey comprising 15 languages, in which data about 27 attested polysemy patterns in English were collected. Their participants, all native speakers of other languages but with good knowledge of English, were given examples of polysemy patterns (e.g., $\underline{T h e}$ chicken drank some water, The chicken is tasty) and were asked to rate how natural the translation equivalent in their own language was, and to report any other senses that fit the pattern that came to mind. To investigate the generativity of patterns in the other languages, participants were introduced to a newly coined word for the base sense of the pattern (e.g., the animal dax), and asked to rate whether the word could be felicitously extended (e.g., The dax is tasty) in their language. The results showed low variability with respect to the presence of the polysemy patterns investigated across languages: All patterns were present in multiple languages, and most were present in nearly all the languages included in the survey. However, with regard to the specific senses of the patterns that were instantiated across languages, they found considerable variability. For instance, the pattern material-for-artefact is cross-linguistically present but is instantiated in different ways: an example is the linguistic form for 
'glass', which conventionally refers to a drinking vessel in English, a car window in Spanish and a mirror in Russian. Finally - and interestingly - their results suggested that patterns that have more similar senses across languages may also be more generative.

Srinivasan and Rabagliati take their results to be best explained by a model that takes the structure polysemy to be mutually constrained by conventions and conceptual structure: More specifically, according to their 'conventionsconstrained-by-concepts' model, polysemous senses are learned conventions, but the process by which new senses are coined and learned are shaped by cognitive biases which make some sets of senses (related in particular ways) easier to learn than others. According to the authors, this would explain their findings that languages develop different senses (conventions) but that there are commonalities in patterns and senses across languages (cognitive biases). To explain the association between generativity and similarity in senses, they hypothesise that the degree to which a polysemous pattern 'constrains' its senses might play an important role. An example of a pattern that 'tightly constrains' its senses is the animal-meat alternation, in that knowing that a chicken is a kind of animal leaves no doubt about what the denotation of chicken is when it is used in a meat sense. A pattern such as material-for-artefact is more 'loosely constraining', in that an artefact use of glass could in principle refer to several different objects made of glass (e.g., drinking vessels, windows, mirrors, etc.). The suggestion is that if a pattern constrains its senses more tightly, languages will be similar in the way these senses are instantiated, and moreover, the relation between them will be easier to abstract and generalise to novel uses. Finally, the authors speculate that patterns of polysemy might be rooted in children's cognitive biases in language learning (e.g., about how an entity's properties might be related to one another), where polysemy might arise as a way of reducing the arbitrariness in the mapping between word forms and concepts, and speeding up learning by allowing children to spontaneously infer new word senses. 


\section{Polysemy from an applied perspective}

Through this introduction we have had an opportunity to see that polysemy can be approached from different perspectives and using different methodologies. The different papers collected in this volume show what kind of findings different methods provide, and also how these different research methodologies can interact and converge in order to evaluate the merits and demerits of particular accounts. Kris Heylen, Thomas Wielfaert, Dirk Speelman, and Dirk Geeraerts' contribution to this volume is the only one directly focused on methodological issues. In their paper, they present recent developments in the corpus-based and computer-assisted study of lexical polysemy. More specifically, they introduce Word Space Models (WSMs), a technique that was originally developed in statistical natural language processing for the task of automatic word sense disambiguation, but which is currently being developed as a tool to support lexicological and lexicographic analyses of word meaning in large corpora (Turney \& Pantel, 2010).

Heylen et al. start their discussion by pointing out that Word Space Models, or Distributional Semantic Models, are a logical extension of the statistical corpus analysis methods that are already established in the field. On the one hand, they are a generalisation of statistical collocation analyses in that they also use word co-occurrence patterns in corpora to infer word meaning, but rather than manually interpreting the collocations of individual lexemes, they systematically compare the collocational profiles of a large set of lexemes, and they use statistical cluster analysis to group corpus patterns into sets of patterns that are indicative of the same meaning. In the latter respect, WSMs are also similar to the 'behavioural profile' approach that has been used in cognitive linguistics for polysemy research since the mid-nighties. But whereas behavioural profiles usually rely on manually coded semantic properties, WSMs use automatically retrieved, directly observable corpus patterns. By combining the corpus-driven approach from collocation analysis with the statistical structure finding of behavioural profiles, Word Space Models can identify the different meanings and usages of a lexeme in an automatic and bottom-up way in large amounts of corpus data. The authors argue that the 'big data approach' offered by Word 
Space Models is an essential extension to the lexicologist's and lexicographer's toolkit, for two reasons: First, the ever growing amount of available text data causes an exponential increase in the number of attestations that have to be processed in a lexical description to arrive at an adequate description of a lexeme's semantics and use. WSMs allow us to deal with this data deluge by prestructuring attestations into possible senses which can then be analysed in further detail. Secondly, large amounts of data allow scholars to investigate trends and patterns that could not be studied in smaller corpora, e.g. the spreading of new words or new usages of existing words through social networks. Here, WSMs offer a semantically-informed trend analysis method. In the remainder of their contribution, Heylen et al. offer a non-technical introduction to the basic principles of WSMs and how they allow to group attestations of a polysemous item by their different meanings and uses. Additionally, they introduce a method to visualize the output of WSMs so that a lexical scholar can inspect and interact with the semantic patterns detected in the attestations. With a test case for the Dutch polysemous lexeme monitor, they show that WSMs in their current state of development are able to find lexicologically relevant patterns, but that further study of the exact relation between corpus patterns and semantics is needed to improve the models. To that end, they show how their visualisation allows the lexicologist to analyse which corpus patterns the model used to group an attestation together with one set of attestations rather than another. The contribution concludes with an outlook onto how WSMs can be further integrated into, and optimized for the linguistic study of word meaning, including the combination of a semasiological with an onomasiological perspective, and the addition of lectal factors like regional or register differences.

\section{Concluding remarks}

In this introduction, we have given an overview of the central topics in the current inter-disciplinary research on polysemy, and of the main proposals on the table. Two main concerns in the contemporary discussion have been identified: the question of how the different senses of a polysemous expression are represented and stored, and the question of how new senses arise and 
eventually establish as senses of a polysemous term. We have seen that most contemporary researchers do not support the sense enumeration model, in which polysemy and homonymy are treated mostly alike. While an alternative model (or models, possibly) is still under development, much progress has been made in recent years when it comes to inter-disciplinary integration, in terms of shared evidence, taxonomies and hypotheses. With this volume, we hope to make a significant contribution to this on-going integration.

The debate concerning the underlying basis for polysemy -- whether it is (mostly) linguistic, cognitive or communicative -- is a relatively recent one on the current interdisciplinary agenda. We hope that our volume might contribute to inspire further research on these issues, which will also include much-needed evidence from development, lexical acquisition, and cross-linguistic variation.

We are very happy to present this up-to-date collection of papers on polysemy. The volume stems from a workshop organized by the editors, and held in Vitoria, the Basque Country, in the autumn of 2012. The workshop was funded by MINECO (Spanish Government) as part of the research project Language and Thought: Lexical Meaning (Code FFI2011-30074-C02-02). That workshop was our first attempt to bring together scholars from different disciplines working on polysemy. The event was a great success, and is the reason why we both thought that this kind of volume would make an important contribution to the research on polysemy, which we regard as a very fascinating and surprisingly understudied phenomenon. We hope the reader will be as excited about this volume as we are.

We would like to acknowledge the help and patience of the people at Lingua. We are grateful to The Executive Editor Johan Rooryck for deciding to accept our proposal for a special issue on polysemy and to The Special Issues Editor Anikó Liptak for her steady guidance, thoughtful responses and good disposition with us. Many thanks also to Lisa Gordon and Sara Bebbington at Elsevier for their efficient and reliable help with various administrative parts of the editorial process. We would also like to express our gratitude to the reviewers, who provided thoughtful and constructive feedback on the papers. Finally, we wish to 
thank the authors of all submitted papers, without whom this special issue would not have been possible.

\section{References}

Allwood, J. (2003). Meaning potentials and context: Some consequences for the analysis of variation in meaning. In H. Cuyckens, R. Dirven \& J. R. Taylor (Eds.), Cognitive Approaches to Lexical Semantics (pp. 29-66). Berlin: Mouton de Gruyter.

Apresjan, J. D. (1974). Regular polysemy. Linguistics, 14(2), 5-32.

Aronoff, M. (1976). Word Formation in Generative Grammar. Cambridge Massachusetts: The MIT Press.

Asher, N. (2011). Lexical Meaning in Context. Cambridge: Cambridge University Press.

Asher, N., \& Lascarides, A. (2003). Logics of Conversation. Cambridge: Cambridge University Press.

Azuma, T., \& van Orden, G. C. (1997). Why safe is better than fast: The relatedness of a word's meanings affects lexical decision times. Journal of Memory and Language, 36, 484-504.

Bierwisch, M., \& Schreuder, R. (1992). From concepts to lexical items. From concepts to lexical items, Cognition(42), 23-60.

Blutner, R. (1998). Lexical pragmatics. Journal of Semantics, 15(2), 115-162.

Bosch, P. (2007). Productivity, polysemy and predicate indexicality. In H. Zeevat \& B. ten Cate (Eds.), Proceedings of the Sixth International Tblisi Symposium on Language, Logic and Computation. Heidelberg/Berlin: Springer.

Briscoe, T., Copestake, A., \& Lascarides, A. (1995). Blocking. In P. Saint-Dizier \& E. Viegas (Eds.), Computational lexical semantics. Cambridge: Cambridge University Press.

Brugman, C. (1988). The Story of over: Polysemy, Semantics, and the Structure of the Lexicon. New York: Garland.

Brugman, C., \& Lakoff, G. (1988). Cognitive topology and lexical networks. In S. Small, G. Cottrell \& M. Tannenhaus (Eds.), Lexical Ambiguity Resolution: Perspectives from Psycholinguistics, Neuropsychology and Artificial Intelligence (pp. 477-507). San Mateo, California: Morgan Kaufman.

Carston, R. (2002). Thoughts and Utterances: The Pragmatics of Explicit Communication. Oxford: Blackwell Publishers.

Carston, R. (2012). Word meaning and concept expressed. The Linguistic Review, 29(4), 607-623.

Copestake, A., \& Briscoe, T. (1992). Lexical operations in a unification-based framework. In J. Pustejovsky \& S. Bergler (Eds.), Lexical Semantics and Knowledge Representation, Proceedings of the First SIGLEX Workshop (pp. 101-119). Berlin: Springer-Verlag.

Copestake, A., \& Briscoe, T. (1995). Semi-productive polysemy and sense extension. Journal of Semantics, 12(1), 15-67.

Cruse, D. A. (1986). Lexical Semantics. Cambridge: Cambridge University Press. 
Cruse, D. A. (2004a). Meaning in Language: An Introduction to Semantics and Pragmatics. Oxford: Oxford University Press.

Cruse, D. A. (2004b). Lexical facets and metonymy. Ilha do Desterro, 47, 73-96.

de Almeida, R. G. (2004). The effect of context on the processing of type-shifting verbs. Brain and Language, 90(1-3), 249-261.

de Almeida, R. G., \& Dwivedi, V. D. (2008). Coercion without lexical decomposition: Type-shifting effects revisited. Canadian Journal of Linguistics, 53(2/3), 301326.

Egg, M. (2011). Semantic Underspecification. In C. Maienborn, K. von Heusinger \& P. Portner (Eds.), Semantics: An International Handbook of Natural Language Meaning (pp. pp?). Berlin: Mouton de Gruyter.

Evans, V. (2009). How Words Mean: Lexical Concepts, Cognitive Models and Meaning Construction. Oxford: Oxford University Press.

Evans, V. (2013). Language and Time: A Cognitive Linguistic Approach. Cambridge: Cambridge University Press.

Evans, V., \& Green, M. (2006). Cognitive Linguistics: An Introduction. Edinburgh: Edinburgh University Press.

Falkum, I. L. (2007). Generativity, relevance and the problem of polysemy. UCL Working Papers in Linguistics, 19, 205-234.

Falkum, I. L. (2011). The Semantics and Pragmatics of Polysemy: A RelevanceTheoretic Account. (PhD), University College London.

Fodor, J. A. (1998). Concepts: Where Cognitive Science Went Wrong. Oxford: Oxford University Press.

Fodor, J. A., \& Lepore, E. (2002). The Compositionality Papers. Oxford: Clarendon Press.

Foraker, S., \& Murphy, G. L. (2012). Polysemy in sentence comprehension: Effects of meaning dominance. Journal of Memory and Language, 67(4), 407-425.

Frazier, L., \& Rayner, K. (1990). Taking on semantic commitments: Processing multiple meanings vs. multiple senses. Journal of Memory and Language, 29(2), 181-200.

Frisson, S. (2009). Semantic underspecification in language processing. Language and Linguistics Compass, 3(1), 111-127.

Geeraerts, D. (1993). Vagueness's puzzles, polysemy's vagaries. Cognitive Linguistics, $4(3), 223-272$.

Geeraerts, D. (2010). Theories of Lexical Semantics. Oxford: Oxford University Press.

Gillon, B. S. (1992). Towards a common semantics for English count and mass nouns. Linguistics and Philosophy, 15(6), 597-639.

Gillon, B. S. (1999). The lexical semantics of English count and mass nouns. In E. Viegas (Ed.), The Breadth and Depth of Semantic Lexicons (pp. 19-37). Dordrecht: Kluwer Academic Publishers.

Jackendoff, R. (1992a). What is a concept, that a person may grasp it? Languages of the Mind: Essays on Mental Representation (pp. 21-52). Cambridge, Massachusetts: MIT Press.

Jackendoff, R. (1992b). Mme. Tussaud meets the binding theory. Natural Language and Linguistic Theory, 10, 1-31.

Katz, J. J. (1972). Semantic Theory. New York: Harper \& Row.

Kempson, R. M. (1977). Semantic Theory. Cambridge: Cambridge University Press. 
Kilgarriff, A. (1992). Polysemy. PhD Thesis, University of Sussex.

Klein, D. E., \& Murphy, G. L. (2001). The representation of polysemous words. Journal of Memory and Language, 45(2), 259-282.

Klepousniotou, E., \& Baum, S. R. (2007). Disambiguating the ambiguity advantage effect in word recognition: An advantage for polysemous but not homonymous words. Journal of Neurolinguistics, 20(1), 1-24.

Klepousniotou, E., Titone, D., \& Romero, C. (2008). Making sense of word senses: the comprehension of polysemy depends on sense overlap. Journal of Experimental Psychology: Learning, Memory, and Cognition, 34(6), 15341543.

Lakoff, G. (1987). Women, Fire, and Dangerous Things: What Categories Reveal about the Mind. Chicago, Illinois: The University of Chicago Press.

Langacker, R. W. (1984). Active zones. Proceedings of the annual meeting of the Berkeley Linguistics Society, 10, 172-188.

Langacker, R. W. (1988). A usage-based model. In B. Rudzka-Ostyn (Ed.), Topics in Cognitive Linguistics (pp. 127-161). Amsterdam, Philadelphia: John Benjamins.

Luo, Z. (1994). Computation and Reasoning: A Type Theory for Computer Science. Oxford: Oxford University Press.

Maienborn, C. (2011). Two-level semantics: Semantic form and conceptual structures. In C. Maienborn, K. von Heusinger \& P. Portner (Eds.), Semantics: An International Handbook of Natural Language Meaning (pp. 709-740). Berlin: Mouton de Gruyter.

McElree, B., J., Matthew, Traxler, M. J., Pickering, M. J., Seely, R. E., \& Jackendoff, R. (2001). Reading time evidence for enriched composition. Cognition, 78, 1725.

Norrick, N. R. (1981). Semiotic Principles in Semantic Theory. Amsterdam: John Benjamins.

Nunberg, G. (1979). The non-uniqueness of semantic solutions: Polysemy. Linguistics and Philosophy, 3(2), 143-184.

Ostler, N., \& Atkins, B. T. S. (1992). Predictable meaning shift: Some linguistic properties of lexical implication rules. In J. Pustejovsky \& S. Bergler (Eds.), Lexical Semantics and Knowledge Representation, Proceedings of the First SIGLEX Workshop (pp. 87-100). Berlin: Springer.

Paradis, C. (2004). Where does metonymy stop? Senses, facets, and active zones. Metaphor and Symbol, 19(4), 245-264.

Pelletier, F. J. (1975). Non-singular reference: some preliminaries. Philosophia, 5(4), 451-465.

Pickering, M. J., McElree, B., \& Traxler, M. J. (2005). The difficulty of coercion: A response to de Almeida. Brain and Language, 93, 1-9.

Pustejovsky, J. (1995). The Generative Lexicon. Cambridge, Massachusetts: The MIT Press.

Pustejovsky, J. (2005). A survey of dot objects. Author's Weblog.

Pylkkänen, L., Llinás, R., \& Murphy, G. L. (2006). The representation of polysemy: MEG evidence. Journal of Cognitive Neuroscience, 18(1), 97-109.

Rabagliati, H., Marcus, G.F., \& Pylkkänen, L. . (2011). Rules, radical pragmatics and restrictions on regular polysemy. Journal of Semantics, 28, 485-512. 
Rappaport Hovav, M. (2014). Lexical content and context: The causative alternation in English revisited. Lingua, 141, 8-29.

Rayner, K., \& Duffy, S. A. (1986). Lexical complexity and fixation times in reading: effects of word frequency, verb complexity, and lexical ambiguity. Memory and Cognition, 14, 191-201.

Recanati, F. (2004). Literal Meaning. Cambridge: Cambridge University Press.

Rodd, J., Gaskell, G., \& Marslen-Wilson, W. (2002). Making sense of semantic ambiguity: Semantic competition in lexical access. Journal of Memory and Language, 46(2), 245-266.

Ruhl, C. (1989). On Monosemy: A Study in Linguistic Semantics. Albany, New York: State University of New York Press.

Sandra, D. (1998). What linguists can and can't tell you about the mind: A reply to Croft. Cognitive Linguistics, 9(4), 361-378.

Sperber, D., \& Wilson, D. (1986/1995). Relevance: Communication and Cognition. Oxford: Blackwell.

Sperber, D., \& Wilson, D. (1998). The mapping between the mental and the public lexicon. In P. Carruthers \& J. Boucher (Eds.), Language and Thought (pp. 184200). Cambridge: Cambridge University Press.

Sweetser, E. (1990). From Etymology to Pragmatics: Metaphorical and Cultural Aspects of Semantic Structure. Cambridge: Cambridge University Press.

Taylor, J. R. (2003). Linguistic Categorization. Oxford: Oxford University Press.

Taylor, J. R. (2006). Polysemy and the lexicon. In K. G., M. Achard, R. Dirven \& F. J. Ruiz de Mendoza Ibánez (Eds.), Cognitive Linguistics: Current Applications and Future Perspectives (pp. 51-80). Berlin: Mouton de Gruyter.

Travis, C. (2008). Occasion-Sensitivity: Selected Essays. Oxford: Oxford University Press.

Turney, P.D., \& Pantel, P. (2010). From Frequency to Meaning: Vector Space Models of Semantics. Journal Artificial Intelligence Research (JAIR), 37, 141-188.

Tyler, A., \& Evans, V. (2003). The Semantics of English Prepositions. Cambridge: Cambridge University Press.

Vicente, A. (2012). On Travis cases. Linguistics and Philosophy, 35, 3-19.

Vicente, A., \& Martínez-Manrique, F. (2015). The big concepts papers: a defence of hybridism. British Journal for the Philosophy of Science, DOI: 10.1093/bjps/axu1022.

Wilson, D., \& Carston, R. (2007). A unitary approach to lexical pragmatics: Relevance, inference and ad hoc concepts. In N. Burton-Roberts (Ed.), Pragmatics (pp. 230-259). London: Palgrave.

Wilson, D., \& Sperber, D. (2004). Relevance theory. In L. R. Horn \& G. L. Ward (Eds.), The Handbook of Pragmatics (pp. 607-632). Oxford: Blackwell.

Wilson, D., \& Sperber, D. (2012). Meaning and Relevance. Cambridge: Cambridge University Press.

Zwicky, A., \& Sadock, J. (1975). Ambiguity tests and how to fail them. In J. P. Kimball (Ed.), Syntax and Semantics, Volume 4 (pp. 1-36). New York: Academic Press. 